\title{
Research on High Brightness Light Source Equipment for Wind Tunnel Test
}

\author{
$X U E \mathrm{Fei}^{1,{ }^{*}}$, MING Chengdong ${ }^{2}$, WANG Huaqiang ${ }^{3}$, WANG Yuchao $^{1}$ \\ ${ }^{1}$ China Academy of Aerospace Aerodynamics, Beijing, P.R. China \\ ${ }^{2}$.The $9^{\text {th }}$ designing of china aerospace science industry corp, Wuhan, P.R. China \\ ${ }^{3}$.Beijing Institute of Control Engineering, Beijing, P.R. China
}

\begin{abstract}
The experimental technology of high brightness light source was studied in sub-transonic supersonic wind tunnel. The elevation light source should be installed on the smooth wall of the tunnel, and the elevation camera should be installed in the safe area of the lower wall of the wind tunnel. The falling image of the missile model in the test is reflected into the elevation camera through a reflector mounted on a curved knife. The full trajectory images and aerodynamic parameters of projectiles of embedded weapons in aircraft can be obtained by the wind tunnel dual-view angle, high brightness light path system and six-degree-of-freedom image analysis system. The newly developed high brightness light source system makes the image clearer and the accuracy of model angle of attack identification less than 0.2 degrees, which is conducive to the analysis of model trajectory. The optical system is designed reasonably, so that the motion trajectory and six-degree-of-freedom data of the model can be obtained easily by using the dual-view technology. Wind tunnel tests under complex aerodynamic conditions of sub-transonic supersonic and multi-body interference have been completed, and all parameters have reached or surpassed the existing technical indicators, meeting the requirements of wind tunnel test research on ejection of embedded weapons in aircraft.
\end{abstract}

\section{Introduction}

Embedded weapons have many advantages, including reducing radar detection rate, reducing aerodynamic drag, increasing the range of bombers, etc. From the old B-25 to the latest F-22, many American aircraft use embedded capsules to carry weapons [1-2]. However, studies show that there are complex dynamic aerodynamic loads [3-6] on the interior surface of the missile cabin. Especially under sub-transonic conditions, the flow in the cabin is the most complex, which will bring great hidden dangers to the flight safety of the aircraft [7-8]. The airflow in the chamber is unstable, but the separation of the loads must be absolutely reliable[9-11]. Therefore, it is necessary to study the separation of the loads in the chamber.

In this regard, many research institutions at home and abroad have also carried out more exploration. In 1983, Robert L. of NASA Langley Research Center and others used wind tunnel tests to study the effect of different sizes of embedded capsules on missile separation under the condition of $\mathrm{Ma}=2.36$ [12]. In 2004, William B. Baker and others at Arnold Air Force Base of the United States carried out numerical simulation on the launch of F-22's internal and external stores, and compared them with flight test data [8]. In 2009, Lockheed's Monique L. Purdon et al. carried out numerical simulation of F-35 buried weapon delivery, and carried out load test and flight test for different loads [13]. In 2012, Mark F. Reeder of the American Air Force Institute of Technology and others built a test platform to simulate the buried ballistic chamber. The free-throwing experiment of suspended objects with zero initial release velocity was carried out under the condition of $\mathrm{Ma}=2.94$. The effects of serrated flow control device on the wall shear layer and the trajectory of falling objects were studied, and the experiment was validated by numerical simulation [2]. Many units and individuals in China have

\footnotetext{
* Corresponding author: 12.9258@163.com
} 
carried out numerical simulation studies on the issue of the delivery of embedded weapons.

Aiming at the problem of embedded weapon delivery, domestic and foreign institutions have carried out a more detailed discussion. However, most of the methods used are steady or quasi-steady, which is inconsistent with the complex aerodynamic forces and the coupled characteristics of motion and aerodynamics in the separation process. Moreover, in order to ensure the safe separation of aircraft and missiles in real flight, most missiles launch [14-16] by ejection, and the missiles need to obtain larger separation velocity and angular velocity [16] in a very short time. Obviously, it is not credible to use steady or quasi-steady methods to study the problem of the delivery of embedded weapons. Therefore, a wind tunnel test technology based on kinematics similarity theory is urgently needed to study the problem of embedded weapon delivery. This paper will focus on this, and establish a set of test technology that can truly simulate the process of launching embedded weapons.

\section{Technical Requirements}

The main difficulties in optical path design are as follows:

(a) Because the object is in a high-speed motion state, the exposure time of the picture is very short. In order to maintain a certain clarity of the image, it is necessary to have sufficient brightness of the object and the background, otherwise the image is dimmed and cannot be identified. Especially for the upward looking light path, how to arrange the light source on the smooth wall of the tunnel is a big difficulty.

(b) The experiment adopts dual-view image acquisition technology, and the two light paths need to complete the shooting work independently. Especially because of the narrow space in the wind tunnel, the installation of the camera and the arrangement of the light paths in the upward-looking light path are difficult problems.

\section{SOLUTIONS AND IMPLEMENTATION PLANS 3.1 light source}

The upright light source should be installed on the smooth wall of the tunnel, as shown in Figure 4 . The light source uses 49 LED light source boards with a power of 100 watts and a luminous flux of 400,000 lumens. The LED light source board is installed in the groove of the lower wall of the re-machined wind tunnel to reduce the interference of the light source board on the flow field.

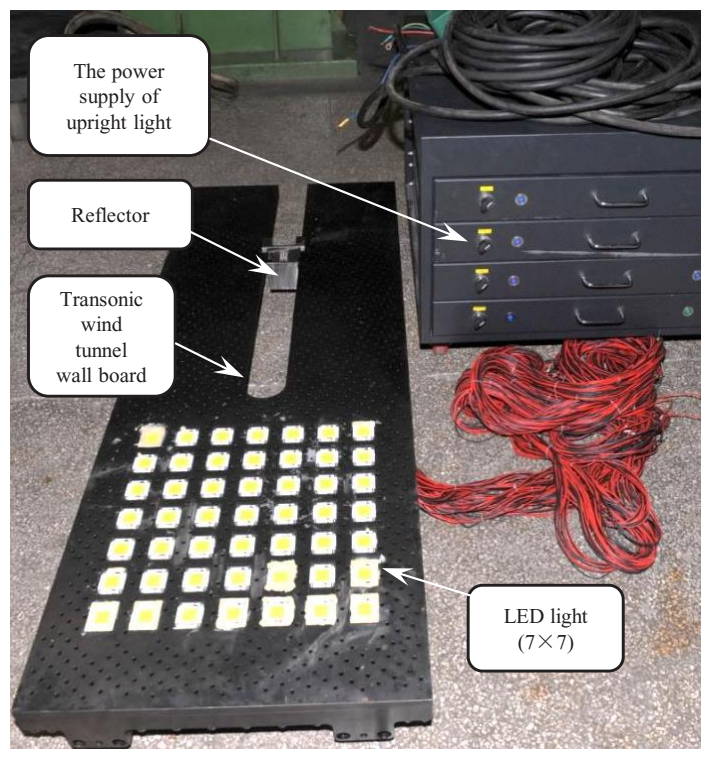

Fig.1 The latest upright light source

The high-speed camera shutter frequency of $2000 \mathrm{~Hz}$ can still ensure the clarity of the object, exposure time of 0.5 $\mathrm{ms}$, to meet the technical requirements. Fig. 1 shows the wind tunnel effect of the elevation light source.

Figure 2 is a sketch of the elevation path. The elevation camera is installed in the safe area of the lower wall of the wind tunnel, and the falling image of the missile model is reflected into the elevation camera through a reflector mounted on a curved knife in the test.

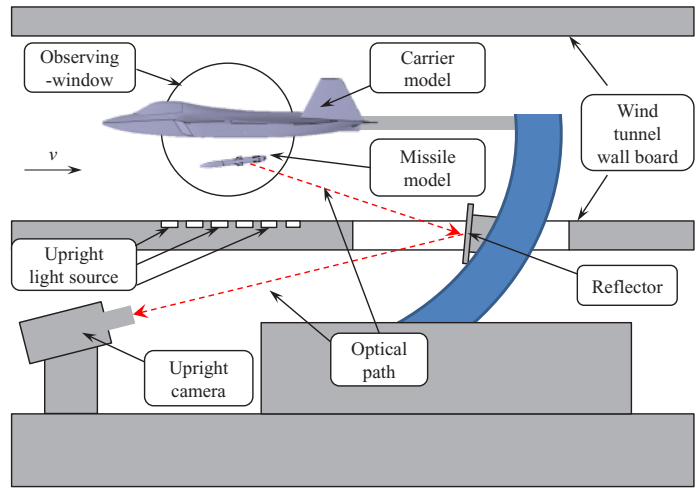

Fig.2 Upright optical path

\subsection{Image data analysis}

Attitude calibration can identify the 6-DOF parameters of missile after obtaining the shooting pictures. The calibration is to place a model with known 6-DOF parameters in the falling area of the missile. The image 
is taken by two cameras, and then matched with the 6DOF components to get the corresponding relationship between the image and the model.

The foreground targets are obtained by background subtraction, median filtering, shadow removal, mathematical morphology processing and communication domain analysis. The $\mathrm{x}, \mathrm{y}, \mathrm{Z}$ coordinates of the center of mass, elevation angle and yaw angle of the model are obtained by face-to-face and elevation view recognition, and then the roll angle of the model is obtained by model matching.

Image recognition is affected by image clarity, pixels, target location method, model boundary identification algorithm and other factors. It is a key technology of this experiment technology.

\section{Test Verification}

The ejection test of the embedded weapon in the $0.6 \mathrm{x}$ $0.6 \mathrm{~m}$ transsonic wind tunnel has been carried out smoothly. The missile dropping process is shown in Fig. 4. More than 20 different state tests have been completed. The number of tests exceeds 60, including the tests of varying $\mathrm{Ma}$, angle of attack, pressure and attitude of missiles. The test successfully completed the scheduled task, and all parameters met the set technical requirements. Especially, the independent and continuous adjustment of ejection velocity and angular velocity is realized, and the reliable ejection of the missile with arbitrary wind load and $\mathrm{Ma}$ is realized.

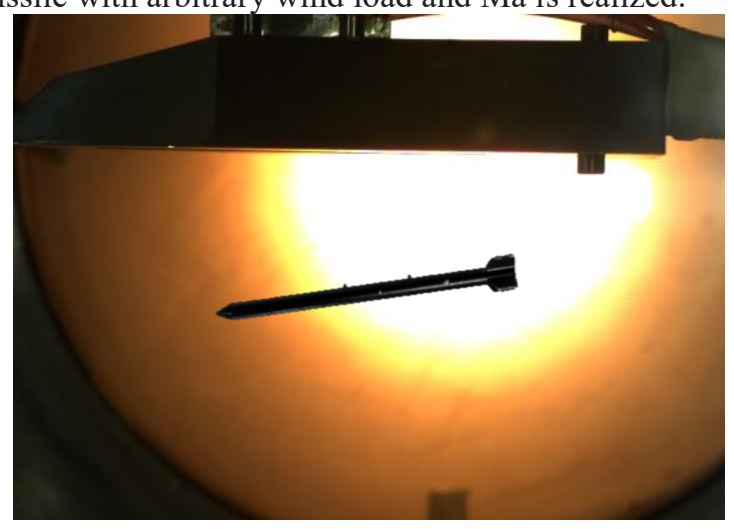

Fig.3 The picture shoot by horizontal camera

\section{Conclusion}

In view of the shortcomings of the launch test of embedded weapons at home and abroad, this paper puts forward the improvement points of the launch test, and develops a new ejection technology for these improvement points. By improving the illumination system of light path, the image sharpness is higher, the generation of virtual image is reduced, and the 6-DOF parameters of the model are identified. By using the dual-view image acquisition technology, especially the layout of the elevation light path system, the details of the model motion are displayed to the greatest extent from multiple angles. The new technology has been tested in the range of Ma 0.4-1.7; the time interval of two consecutive pictures is less than $0.5 \mathrm{~ms}$; and the accuracy of model angle of attack identification is less than 0.2 degrees.

\section{References}

1. TANG Shangqin, HUANG Changqiang, WENG Xingwei. The Study on Trajectory of Missile Separating from Cavity with Aerodynamic Interference Considered.Journal of Projectiles[J]. Rockets,Missiles and Guidance.2013. 33 (3): 138142(in Chinese).

2. SHI Ai-ming, YE Zheng-yin, YANG Yong-nian. Calculation and Analysis for Aerodynamic LoadsActing on InteriorWeapon Cabin $\forall \mathrm{s}$ Door[J]. Aeronautical Com puting Techn ique. 2007. 37 (3): 5-6(in Chinese).

3. Scott T. Bjorge. FLOW AROUND AN OBJECT PROJECTED FROM A CAVITY INTO A SUPERSONIC FREESTREAM[R]. AFIT/GAE/ENY/04-M02,2014.

4. Thomas J. Flora. FREEDROP TESTING AND CFD SIMULATION OF ICE MODELS FROM A CAVITY INTO SUPERSONIC FLOW[R]. AFIT/GAE/ENY/12-S15,2012.

5. J. Shipman, S. Arunajatesan, P.A. Cavallo, R.et al. Flow Control for Enhanced Store Separation. AIAA 2007-1239[R], Reston: AIAA, 2007.

6. Justin D. Merrick. INFLUENCE OF MACH NUMBER AND DYNAMIC PRESSURE ON CAVITY TONES AND FREEDROP TRAJECTORIES[R]. AFIT-ENY-14-M-36,2014.

7. William B. Baker, Jr.Scott Keen, Charles Morgret. Validation of Weapon Separation Predictions Using F/A-22 Flight Test Results. AIAA 2004-6803[R], Reston: AIAA, 2004.

8. XUE Fei, JIN Xin, WANG Yuchao. Experimental investigation on the high speed weapon delivery from internal weapons bay. [J]. Acta Aeronautica et Astronautica Sinica, 2017.38(1):120114.

9. XUE Fei, Qin Han, Wang yuchao. Free flight wind tunnel test similarity law derivation for light store separation from aircraft. Advances in Mechanical Engineering 2019, Vol. 11(5) 1-7. 
10. Ryan Carter, Rick Lind. Parametric Modeling for Store Separation Aerodynamics using System Identi_cation. AIAA 2012-4510[R], Reston: AIAA, 2012.

11. Robert L. Stallings Jr. Store separation from cavities at supersonic flight speeds[R]. VOL. 20, NO. 2,1983 .

12. Monique L. Purdon, Chris F. Hetreed, Dr. Mary L. Hudson. F-35 Pre-Flight Store Separation Analyses: Innovative Techniques for Affordability. AIAA 2009-102[R]. Reston: AIAA, 2009.

13. ZHU Shoutao, CAO Linping, FENG Puwen. Simulation of Missile Separation from Internal Weapon Bay[J]. Electronics Optics \& Control,2012.19(9): 67-71.(in Chinese).

14. Collaborative-Design/Control Simulation in A Missile-hidden Launching Gear and Electrohydraulic Servo-system[C]//, 2005:70-74. (in Chinese).

15. FENG B i-ming, NIE Wan-sheng, CHE Xue-ke. Effect of InitialConditions on Separation Trajectory of the Internal Missile[J]. Rockets,Missiles and Guidance. 2009,27(2):62-65 (in Chinese).

16. CHANG Chao, DING Hai-he. Review on Missile Store Safety Separation Technology of Embedded
Ejection Weapons[J]. MODERN DEFENCE TECHNOLOGY,2012,40(5):67-74 (in Chinese).

17. Scott Keen K. Trajectory Simulations Should Match Flight Tests and Other Lessons Learned in 30 Years of Store-Separation Analysis. AIAA-2009-99[R], Reston: AIAA, 2009.

18. Bidur Khana , Kevin Knowles , Alistair Saddington - Computational study of cavity flowfield at transonic speeds . AIAA 2009701[R], Reston: AIAA, 2009.

19. A. Fedorov,V. Shalaev.PC Desktop Aerodynamic Models for Store Separation from Weapons Bay Cavities and Related Vortical Processes[R]. (SYA) 37-2.

20. YU Jian-gang, SANG Wei-min, LEI Xi-wei. Analysis of the flow characteristics and aerodynamic problems in internal weapons bay [J]. FLIGHT DYNAMICS， 2011,29(2):29-32. (in Chinese).

21. LI Zhou fu. Wind tunnel special tests technique[M]. Beijing: Aviation Industry Press, 2010:104-113.(in Chinese). 